\title{
Rebuttal to Response by Stephen Leonard
}

\section{Stephen Earl Bennett, University of Cincinnati}

$\mathrm{P}$ ofessor Leonard is entitled to assert that research counts for more in our profession than efforts at civic education. That said, it does not advance his case to create false dichotomies when characterizing another's view of how political scientists could help train citizens for the next century.

First, Leonard misconstrues my references to Charles Merriam's and M. Kent Jennings' careers as scholars and contributors to civic education. I did not claim that either gained more fame from the latter than from the former. I argued that both scholars' careers show one can combine quality scholarship and concern with civic education. To assert that one must either engage in scholarship and be lauded by the profession, or engage in civic education and languish in obscurity, creates a false dichotomy.

Second, I am confused by Leonard's claim that I "attempt to resuscitate the civic education credentials of William Bennett Munro." What I did, in an endnote, was show that Leonard distorted what Munro said in his 1927 APSA presidential address. One need not subscribe to Munro's position to note that someone else misreported what he said.

Third, contrary to Leonard's assertion, I pin no hopes on data showing our discipline losing majors, experiencing declining undergradu-

\section{References}

Schachter, Hindy Lauer. 1998. "Civic Education: Three Early American Political Science Association Committees and Their Relevance to Our Times." PS: Political Science and Politics 31(September): 63135 . ate enrollments, and attracting fewer graduate students. APSA's annual reports of political science doctoral students' difficulties in securing academic employment do not cause me to sing hosannas. My point is simple: Can the discipline afford to let negative trends go unchecked? Those who value graduate training need to be involved in civic education efforts if those programs ameliorate trends that limit the number of academic positions open to political scientists. (Am I wrong to believe that political scientists want to see our Ph.D.s gainfully employed?) We don't know if renewed efforts to train primary and secondary students in citizenship will off-set negative trends for our polity and discipline, but doing nothing is not likely to help.

Moreover, since civic education programs will proceed with or without political scientists' involvement-a point which Professor Leonard ignores-I am at a loss to understand why members of our profession would not want to be involved.

Fourth, one wonders why political science should follow disciplines like rhetoric, philosophy, and classics, which, when faced with lessened student interest, clung to research. Political scientists may, indeed, adopt the equivalent of a "Maginot Line," as Professor Leonard claims other disciplines have.
Need I remind my colleagues of what happened to that line in 1940 ? Unlike the French general staff, which planned to fight new wars in old modes, political science needs to be more adaptable.

I am well aware of the weight many universities and departments place on research. I strongly believe that people seeking employment in colleges and universities should engage in research that informs and improves teaching. I am on record as arguing that the "teaching-vs.research" notion is a false dichotomy.

Growing pressures that many institutions of higher education face to deemphasize research and give more weight to teaching in personnel actions are worrisome. Fortunately, as a few scholars like Merriam and Jennings show, one can combine quality research with concern for civic education.

Professor Leonard's pessimism is understandable, but premature. When I place his pessimism alongside Hindy Lauer Schachter's (1998) guarded optimism, however, I opt for the latter. I am not impressed by those who claim that by studying the past we must perforce repeat it. We are condemned to repeat the past when we fail to study and learn from it. Whoever the Bard of Avon was, his take on the past need not be definitive. 